\title{
Proposta de um modelo de referência em notação BPMN para um sistema de MRP
}

Tulio Cremonini Entringer tulio_entringer@hotmail.com

Universidade Estadual do Norte

Fluminense Darcy Ribeiro, Brasil.

Ailton da Silva Ferreira

ailtonsilvaferreira@yahoo.com.br Universidade Federal Fluminense (UFF) Macaé, Rio de Janeiro, Brasil.

\author{
RESUMO
}

As empresas estão, progressivamente, investindo em práticas voltadas para melhorias da qualidade da gestão, com a finalidade principal de habilitá-las a atuar de forma competitiva no presente mercado. Para isso, se faz necessário a documentação das atividades e informações dos processos de negócios existentes na organização, visando redução de tempo e custo na elaboração do modelo particular. Nesse contexto, o objetivo deste trabalho é desenvolver um modelo de referência dos processos do Planejamento de Requisitos de Materiais (MRP), importante módulo do planejamento e controle da produção (PCP). A metodologia de pesquisa empregada neste trabalho foi dividida nas seguintes etapas: estudo do MRP e da modelagem de processos de negócios, definição dos processos do modelo de referência, escolha da metodologia e ferramenta de modelagem de processos, desenvolvimento do modelo de referência e do protótipo do software e, por fim, análise de resultados. A notação de modelagem empregada foi o BPMN, pois é considerada uma linguagem padrão no campo de modelagem de processos. O protótipo foi desenvolvido através da interface Delphi com o intuito de aplicar o modelo no apoio à implantação de programas de gestão empresarial. Como resultados, a partir de uma documentação formal, o modelo mostrou-se um mecanismo útil na compreensão dos processos levantados e apropriado no suporte à implantação de ferramentas de gestão da produção.
\end{abstract}

PALAVRAS-CHAVE: Modelo de Referência; Planejamento de Requisitos de Materiais; Notação de Modelagem de Processos de Negócios. 


\section{INTRODUÇÃO}

As organizações estão, progressivamente, investindo em práticas voltadas para melhorias da qualidade da gestão, com a finalidade principal de habilitá-las a atuar de forma competitiva no presente mercado, tais como: processos de reengenharia, adoção de um sistema de gestão empresarial integrado (ERP), certificações ISO (International Organization for Standardization), produção enxuta, custeio por atividades, entre outras. Entretanto, a grande maioria das ações de melhoria demanda um alto investimento, provoca mudanças no comportamento da empresa e algumas delas possuem um alto custo e longo período de implantação, como por exemplo na adoção de ERP (BREMER; LENZA, 2000; CORREA; SPINOLA, 2015).

Um aspecto comum quando se pretende adotar uma ação voltada para a melhoria da qualidade da gestão empresarial é que a maioria delas exigem que sejam levantadas e documentadas as atividades, informações e recursos dos processos que são realizados pela empresa, isto é, que sejam levantados os Processos de Negócios existentes na organização.

Entretanto, a atividade de modelagem dos processos de negócio ainda não é uma prática comum entre as organizações (THURER; FILHO, 2012), o que colabora para o aumento de custo e de tempo de implantação do sistema ou projetos de melhorias, devido a necessidade de desenvolver novos modelos relativos aos seus Processos de Negócios (BREMER; LENZA, 2000). Se as empresas já possuíssem um modelo de referência, essa atividade não seria necessária. De acordo com Scheer (2000), estudos de casos mostraram que o uso de modelos de referência pode reduzir o custo e o tempo de implantação de projetos organizacionais em até $30 \%$.

No contexto empresarial, um dos Processos de Negócios essenciais para as organizações, principalmente para as localizadas em países como o Brasil, onde as atividades de produção são mais acentuadas que o desenvolvimento de produtos, é o Planejamento e Controle da Produção (PCP). Este processo é responsável pelo levantamento da demanda, planejamento da produção, planejamento da capacidade, gestão de materiais, programação da produção, etc. (FERNANDES; GODINHO FILHO, 2010; MUKHOPADHYAY, 2013).

Dentre os conceitos básicos da hierárquica da função do PCP, referentes ao Planejamento de Materiais, destaca-se o Planejamento de Requisitos de Materiais(Material Requirement Planning - MRP). De acordo com Favaretto (2012), o MRP executa o planejamento detalhado da produção, que faz a liberação de ordens de produção e compra dos componentes dos produtos de acordo com a demanda prevista e os estoques disponíveis.

Segundo Thurer e Filho (2012), a maioria das empresas, em especial as pequenas e médias, tem a ciência de que devem melhorar suas atividades de PCP a fim de obter reduções do "lead time" e de "work in process" e com isso, obter maior eficiência operacional. Contudo, para os autores, as organizações simplesmente não sabem como fazer isso, uma vez que a grande maioria de pesquisas e soluções para o PCP é focada em grandes e complexas empresas.

É importante destacar que o sucesso da modelagem de processos de negócio depende, sobretudo, da seleção apropriada da metodologia utilizada. 
Entre as ferramentas existentes, a Notação de Modelagem de Processos de Negócios (Business Process Model and Notation - BPMN) se configura com uma das linguagens mais utilizadas atualmente pela indústria e universidades (CHINOSI; TROMBETTA, 2012; RECKER, 2010). Entretanto, observa-se na literatura pesquisada, que tal notação ainda é pouco explorada para o desenvolvimento de modelos de referência (ENTRINGER et al., 2018).

Por fim, nota-se uma grande e crescente atenção, tanto do meio acadêmico quanto no empresarial, no desenvolvimento de modelos que apoiem no planejamento de recursos empresarias (CORREA; SPINOLA, 2015). Entretanto, estudos encontrados na literatura direcionados para o desenvolvimento de modelos de PCP são voltados, em sua maioria, para segmentos industriais particulares e que abordam módulos de atividades específicas da gestão da produção.

Com o intuito de apoiar as empresas, em especial as pequenas e médias, no desenvolvimento e implantação de ações de melhorias da gestão empresarial, o presente trabalho tem como objetivo o desenvolvimento de um modelo de referência, em notação BPMN, que aborde os Processos de Negócios relacionados as atividades e processos do MRP.

Adicionalmente, este trabalho também objetiva o desenvolvimento de um protótipo de software através da interface Delphi (linguagem Object-Pascal) a fim gerar uma maior consistência entre a abstração do modelo de referência e sua aplicação no apoio a implantação e desenvolvimento de ferramentas de gestão empresarial.

\section{PLANEJAMENTO DE REQUISITOS DE MATERIAIS}

O MRP é um sistema lógico de cálculo que converte a previsão de demanda em programação da necessidade de seus componentes, sendo predominante presente nos sistemas de PCP nos processos de manufatura (MENDES; FILHO, 2017). Este modelo determina a quantidade e o momento em que se necessita dos módulos, componentes e matérias-primas para produzir uma determinada quantidade de produtos finais, conforme especificado no MPS, considerando os níveis de estoque e os prazos de suprimento (GIROTTI et al., 2016).

Guerra, Schuster e Tondolo (2014) reiteram que por meio do MRP, é possível que as empresas realizem um melhor gerenciamento e acompanhamento dos insumos, matérias-primas, componentes, produtos em elaboração e produtos acabados. Devido à grande complexidade existente em alguns produtos (grande número de itens, componentes, peças e acessórios) a área de PCP utiliza, com bastante frequência o MRP, visando redução dos estoques, obtenção de maior previsibilidade do recebimento dos materiais e insumos, redução do tempo de processamento do produto, assim como atendimento dos prazos de entrega do produto final aos clientes.

Sendo assim, a finalidade do MRP é executar computacionalmente a atividade de planejamento das necessidades de materiais, permitindo assim determinar, precisa e rapidamente, as prioridades das ordens de compra e fabricação.

O MRP é baseado no planejamento das necessidades de acordo com o Plano Mestre de Produção, o qual é preparado de acordo com a demanda dos 
clientes, da lista de materiais (Bill of Materials - BOM) (YENISEY, 2006) e as quantidades em estoques dos itens do BOM (NEELY; BYRNE, 1992).

De acordo com a Figura 1, o MPS fornece para o MRP quais produtos serão produzidos no horizonte de planejamento para o qual se calculará a necessidade de recursos. Já o BOM fornece quais são os itens "pais" e itens "filhos" a serem produzidos de acordo com o MPS, a demanda bruta de cada item e o lead time de produção e de entrega dos fornecedores. Por fim, o arquivo sobre a situação do estoque fornece qual é a quantidade em estoque de cada item para ser subtraída da necessidade bruta e encontrada a necessidade de material para produção durante o horizonte de planejamento adotado (YENISEY, 2006).

Figura 1 - Esquematização da execução do MRP

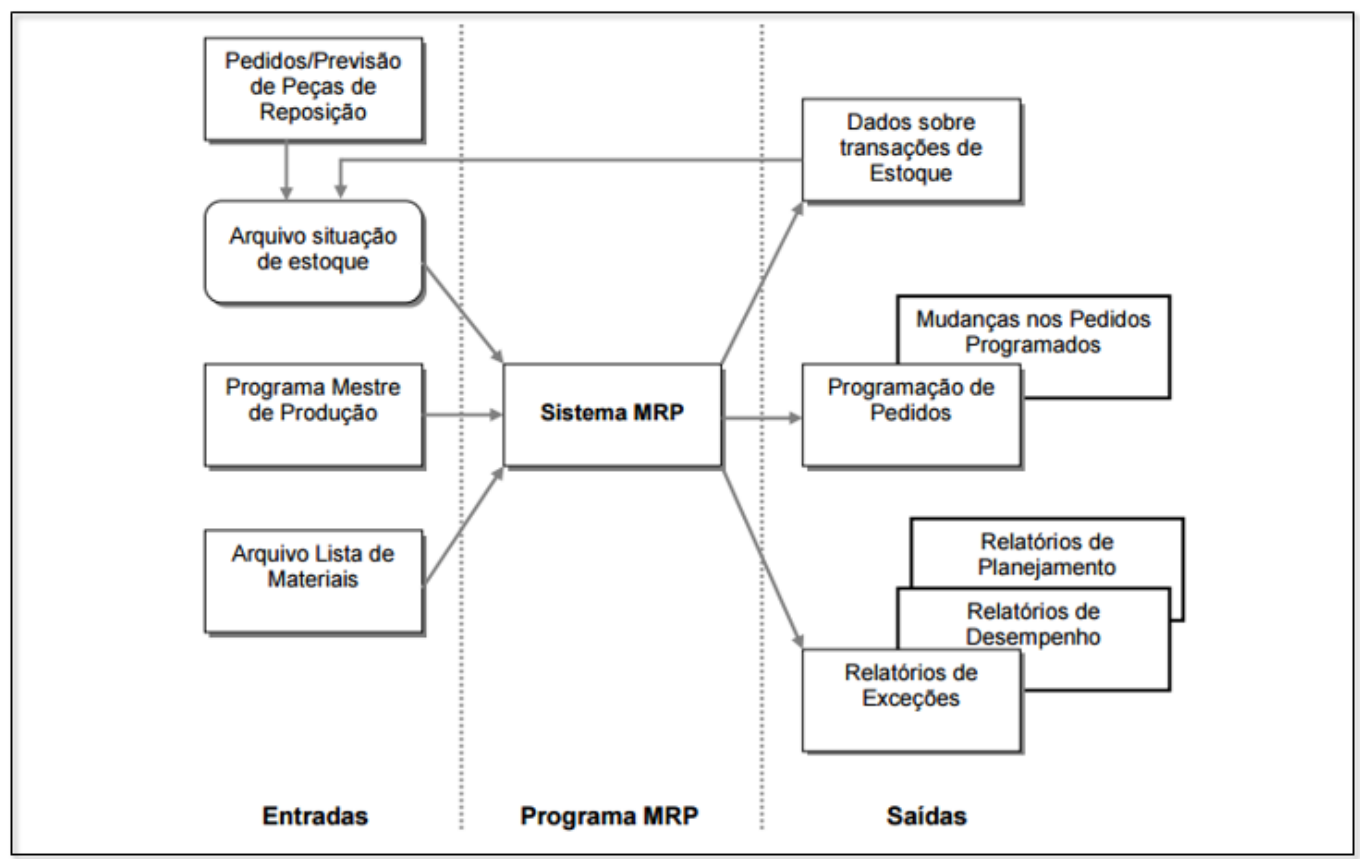

Fonte: adaptado de Gaither e Frazier (2005)

O modelo MRP é caracterizado como um sistema de produção "empurrada", que gera as ordens de produção e compra, conforme o programa mestre de produção, as listas de matérias e os níveis de estoque. A partir dos lead times de produção e compra, determinam-se os instantes em que as ordens devem ser liberadas, aplicando uma lógica de programação para "trás" (GIACON; MESQUITA, 2011).

Godinho Filho e Fernandes (2006), respaldado por Gaither e Frazier (2005), destacam como principais benefícios do MRP são: melhorar o serviço ao cliente, com maior atendimento a prazos e entregas; reduzir os investimentos em estoques; e melhorar a eficiência operacional da organização fabril.

Entretanto, Sagbansua (2010) destaca que a precisão das informações tem um papel vital no MRP, uma vez que os benefícios deste sistema dependem fortemente da disponibilidade do uso de computadores que manterão os dados atualizados sobre as necessidades de um certo componente da produção. 
De acordo com uma pesquisa realizada por Jonsson e Mattsson (2006), $75 \%$ das empresas de manufatura usavam o MRP como o principal método de planejamento de material. Conforme observado por Ornek e Cengiz (2006), Pandey, Yenradee e Archariyapruek (2000) e Taal e Wortmann (1997), a simplicidade relativa dos sistemas MRP os torna preferidos por muitas abordagens de programação matemática.

Para Milne, Mahapatra e Wang (2015), os usuários entendem a lógica MRP e desenvolvem uma boa compreensão das relações entre entradas e saídas desse sistema. Para os autores, esta compreensão permite aos usuários identificar quais dados de entrada estão em erro e quais precisam ser melhorados para obter melhores resultados. Como os usuários de MRP entendem esses relacionamentos de entrada/saída, eles tendem a estar mais confiantes nos resultados de planos de produção por MRP do que os planos de produção emitidos por programas matemáticos de códigos-fonte não conhecidos.

Uma razão adicional para usar o MRP é que muitas grandes corporações possuem licenças para softwares nos quais os módulos MRP estão integrados com outras funções corporativas. Devido a esta integração e simplicidade relativa, os sistemas MRP oferecem flexibilidade gerencial que pode ser difícil de obter em sistemas de planejamento de material baseado em programação matemática (MILNE; MAHAPATRA; WANG, 2015).

O CRP, também conhecido como planejamento das necessidades da capacidade, visa subsidiar as decisões do planejamento detalhado da produção e matérias, MRP (MUKHOPADHYAY, 2013).

Este planejamento, de acordo com Corrêa et al. (2009), tem como objetivos principais a antecipação das necessidades de recursos que requeiram prazo de poucas semanas para sua mobilização e, também, a geração de um plano detalhado de compras e produção que seja viável, por meio de ajustes efetuados no plano original sugerido pelo MRP, para que este possa ser liberado para execução pela fábrica.

O horizonte do planejamento típico é de algumas semanas, sendo que o limite é dado pelo horizonte do MPS, que define o horizonte máximo do MRP. Sendo assim, o período de planejamento da capacidade de curto prazo é de uma semana, como o RCCP (CORRÊA; GIANESI; CAON, 2009).

\section{MODELO DE REFERÊNCIA}

A modelagem de referência é definida como o processo de documentar formalmente um domínio problemático com o objetivo de compreender e comunicar as partes interessadas (SIAU, 2004; SIAU; ROSSI, 2011).

Os modelos de referência, os quais podem ser desenvolvidos em situações reais ou em estudos teóricos, documentam os vários aspectos de um processo de negócio (BREMER; LENZA, 2000). De acordo com Scheer (2000), pode-se distinguir entre modelos procedimentais ou de implementação de softwares padrão, e modelos de negócios tais como modelos para gestão da produção e desenvolvimento de produtos.

Para Vernadat (1996), um modelo de referência deve conter um determinado grau de generalidade e ser customizável. Sendo assim, deve servir 
de base para discussão, uma sugestão formal ou semiformal para a elaboração de modelos específicos, trazendo informações referentes ao projeto de um processo de negócio.Já Keller e Teufel(1998) entendem que os modelos de referência podem ser aplicados nos casos de experiência acumulada em um tipo de negócio, e nas soluções de processos de negócios implementadas e executadas em software de gestão empresariais.

Vojislav e Leon (2000) propõem que a escolha certa dos modelos de referência ajuda a minimizar possíveis erros nas primeiras fases de modelagem e implantação de sistemas de gestão. Isso permite que o design de um processo ou sistema comece com a escolha apropriada dos requisitos e também com o estabelecimento das características adequadas dadas pelo modelo de referência.

De acordo Bremer e Lenza (2000), o objetivo do modelo de referência é prover a empresa com uma solução inicial para seus Processos de Negócios, para que, através dessa, seja especificado e detalhado o modelo particular da empresa.

Bolloju e Leung (2006) sugerem que, durante a fase de análise de um desenvolvimento do sistema de informação, o modelo conceitual pode ser usado para capturar e representar os requisitos de desenvolvimento e implantação de tais tecnologias. Para Scheer (2000), o uso de modelos de referência pode reduzir o custo e o tempo de implantação de projetos organizacionais, como por exemplo, na adoção de ERP.

Resumidamente, segundo Vernadat (2003), as vantagens em se adotar modelos de referência consistem em redução de tempo e custo no desenvolvimento do modelo particular; comparação das atividades da empresa com as atividades propostas no modelo, isto é, melhores práticas; e melhor suporte na implantação de sistemas de gestão empresarial integrados.

O modelo a ser desenvolvido neste trabalho dará maior ênfase às informações e atividades que compõem o processo de MRP, isso porque tem como objetivo principal o suporte na implantação de melhorias organizacionais, como por exemplo, sistemas de gestão empresarial (Figura 2).

Figura 2 - Processo de elaboração do modelo de referência

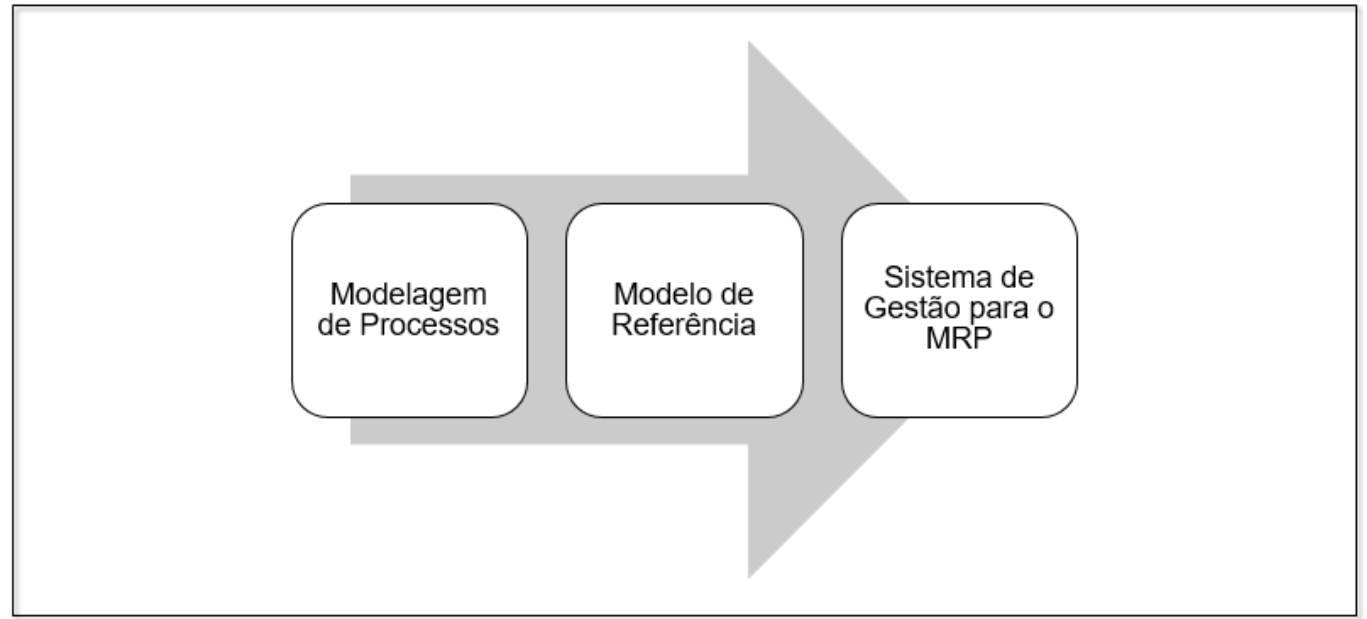

Fonte: Autoria própria (2018) 
Entringer e Ferreira (2018) demonstraram que os modelos de referência se mostram como uma ferramenta viável no apoio do desenvolvimento, seleção ou adoção de sistemas integrados de gestão e softwares, como pôde ser constatado nos trabalhos de Abele e Schrems (2010), Aguilar, Chacal e Bravo (2009), Tatsiopoulos e Mekras (1999) eMeyer, Isenberg e Hubner (1988). Diante nesse cenário da literatura científica na área de modelos de referência e PCP, observase que a proposta deste trabalho, de fato, busca avançar sobre modelos internacionais do planejamento empresarial, preenchendo uma lacuna de pesquisas direcionadas para o desenvolvimento de um referencial conceitual para o MRP, em notação BPMN.

\section{METODOLOGIA DE PESQUISA}

\section{DEFINIÇÃO DO MÉTODO DE PESQUISA}

O modelo de referência foi desenvolvido a partir de estudos teóricos. Assim, esta pesquisa utiliza os procedimentos de pesquisa bibliográfica, uma vez que foi desenvolvida a partir de trabalhos anteriores, como dissertações, artigos e livros sobre o assunto tratado. Desta forma, o trabalho futuro pode ser baseado nas conclusões apresentadas neste artigo, e elaborar hipóteses visando aprofundar o estudo sobre o assunto ou aspectos específicos relacionados.

Por outro lado, esta pesquisa também pode ser classificada como experimental, uma vez que se baseia na criação de um modelo de referência de um sistema de Planejamento e Controle da Produção, modelado por meio de um software. Assim, com o objetivo de desenvolver um modelo de referência e expor a forma como foi desenvolvido a partir da análise das atividades envolvidas nos processos, permitir que este trabalho seja classificado como uma pesquisa descritiva.

\section{ESCOPO DA PESQUISA}

A fase de identificação de processos e hierarquização níveis é considerado o passo-chave na modelagem de processos, visa identificar todos os Processos de Negócios existentes em uma atividade particular de uma organização.

A Figura 3 apresenta o modelo da hierarquia do Processos de PCP relacionando o planejamento da capacidade de seus recursos com o planejamento das necessidades de seus materiais.

A decomposição hierárquica da função PCP começa a partir da compreensão dos conceitos básicos relacionados aos níveis de planejamento de materiais, a saber: Planejamento de vendas \& operações (S\&OP) e Planejamento Agregado (PA); Planejamento Mestre da Produção (MPS); Planejamento das Necessidades de Materiais (MRP) e Programação da Produção (PP) (CORRÊA; CORRÊA, 2012; MUKHOPADHYAY, 2013).

Este trabalho será limitado no desenvolvimento do modelo de referência do MRP e seu respectivo planejamento da capacidade. 
Figura 3 - Hierarquia do planejamento e controle da produção.

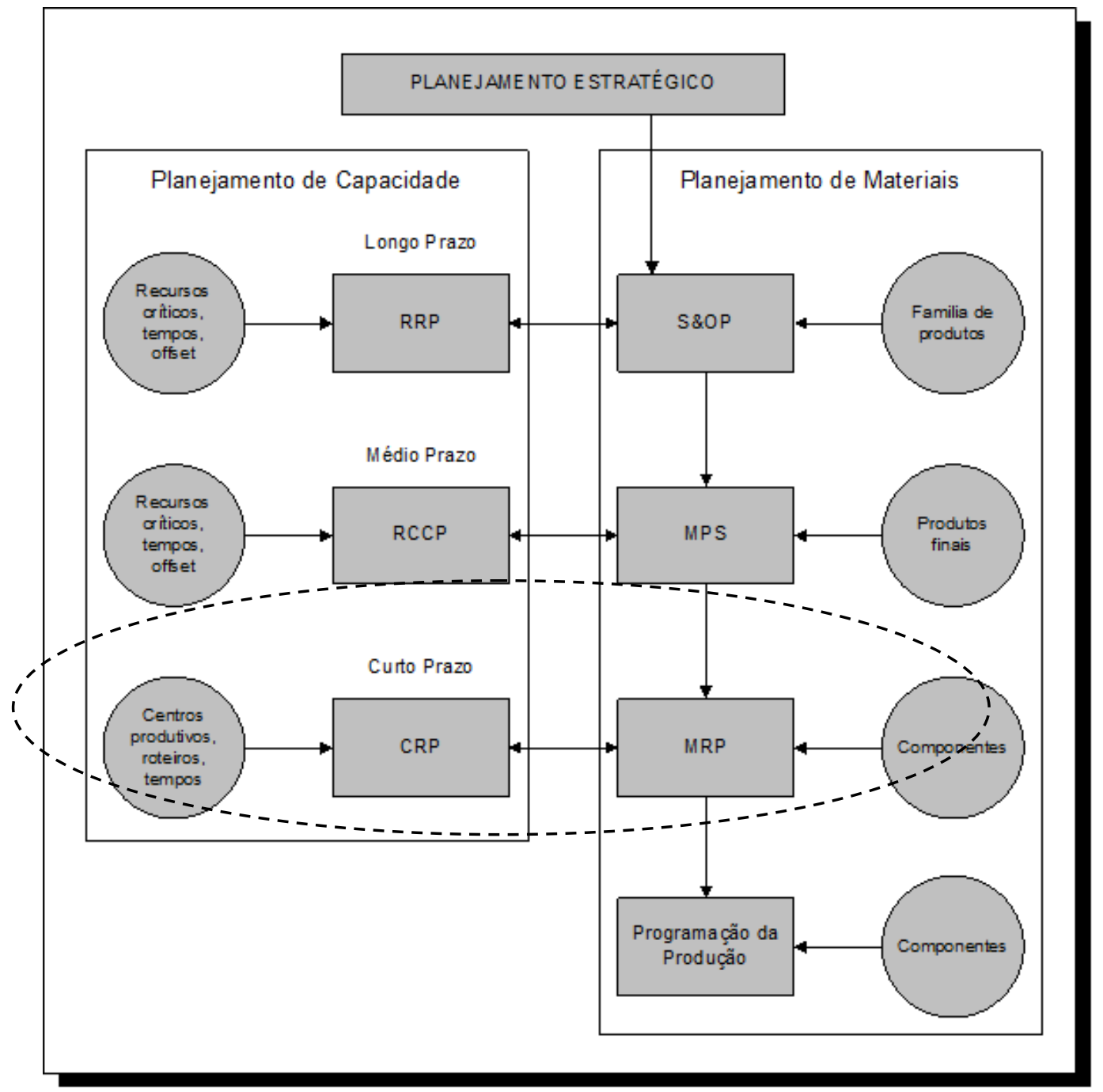

Fonte: adaptado de Corrêa e Corrêa (2012).

\section{ETAPAS DA METODOLOGIA DE PESQUISA}

A metodologia utilizada para a elaboração deste trabalho foi dividida em oito etapas sequenciais, conforme apresentado na Figura 4. 
Figure 4 - Etapas da metodologia de pesquisa

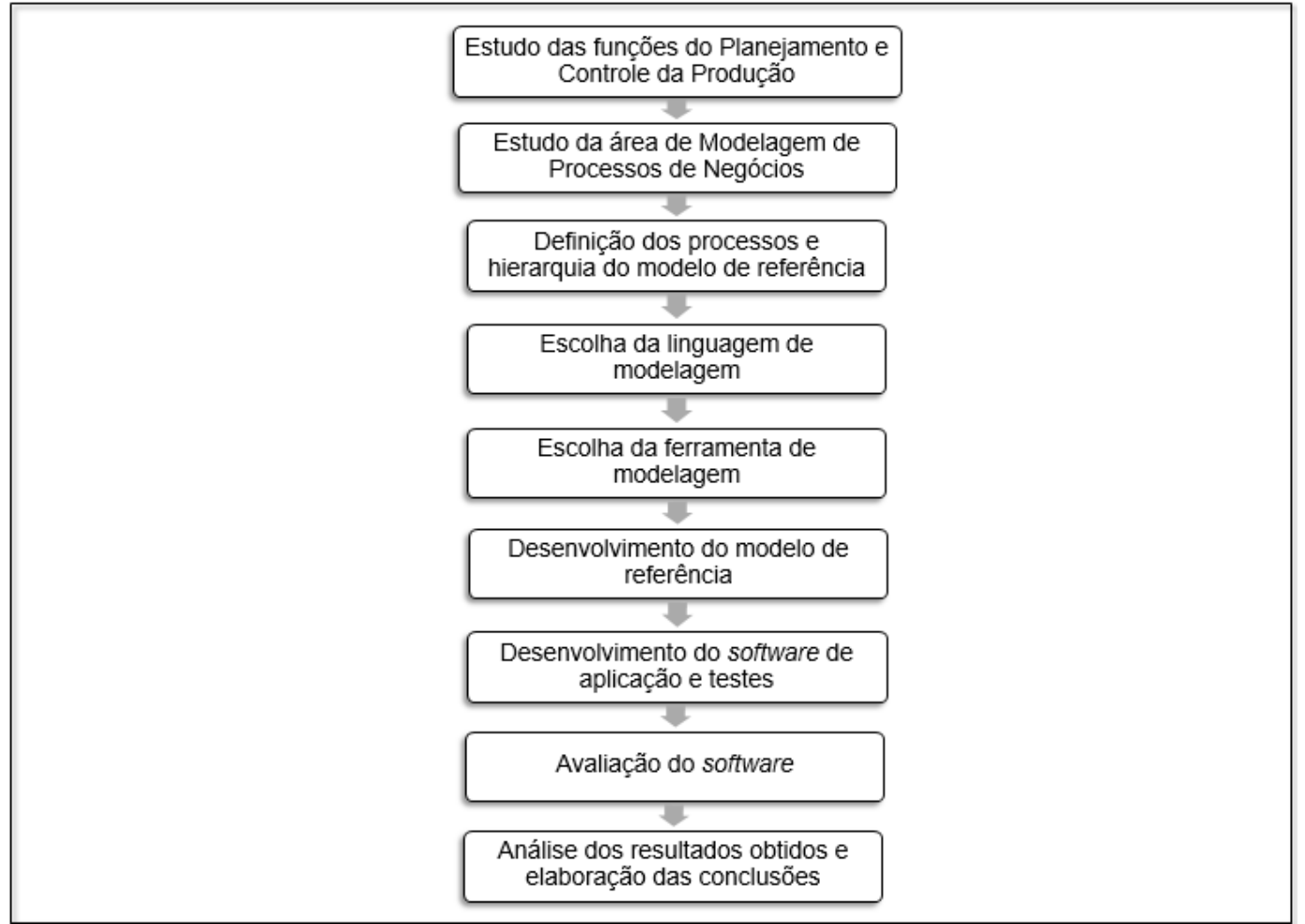

Fonte: Autoria própria (2018)

- Etapa I - Estudo das funções do Planejamento e Controle da Produção: Nesta etapa foram levantadas e estudadas, de acordo com as referências bibliográficas relacionadas ao tópico de estudo, sobre conceitos, atividades e informações e funções de hierarquia típica de planejamento da produção;

- Etapa II - Estudo da área de Modelagem de Processos de Negócios: Na segunda etapa, foram estudadas e analisadas, a partir da literatura cientifica, os conceitos e linguagens a respeito da modelagem de processos, bem como sobre modelos de referência;

- Etapa III - Definição dos processos e hierarquia do modelo de referência: Nesta terceira etapa, após as fases da revisão bibliográfica, foram definidos os processos e hierarquia que irão compor o modelo de referência de um sistema de PCP;

- Etapa IV - Escolha da linguagem de modelagem: Nesta quarta etapa, foi definida a linguagem de modelagem utilizada para o desenvolvimento do modelo de referência. A notação de modelagem selecionada foi o BPMN;

- Etapa V - Escolha da ferramenta de modelagem: Nesta etapa, foi definida a ferramenta de modelagem, no sentido de prover facilidades no entendimento e na visualização do modelo, ou seja, o pleno entendimento das funções de um sistema. A ferramenta de modelagem selecionada foi o Bizagi Process Modeler versão 3.1.0.011;

- Etapa VI - Desenvolvimento do modelo de referência: Nesta etapa, a partir da linguagem e ferramentas de modelagem definidas, foi desenvolvido, baseado na teoria e em notação BPMN, o modelo de referência de um sistema de PCP; 
- Etapa VII - Desenvolvimento do software de aplicação e testes: Na sétima etapa, uma vez elaborado o modelo de referência do sistema de PCP, foi desenvolvido um protótipo de software com a finalidade de aplicar e validar o modelo, a partir da interface Delphi versão 7.0, que utilizada a linguagem ObjectPascal;

- Etapa VIII - Análise dos resultados obtidos e elaboração das conclusões: Na última etapa, foram analisados e discutidos os resultados apresentados nas fases anteriores, bem como as conclusões obtidas e sugestões para trabalhos futuros.

\section{RESULTADOS}

\section{MODELAGEM DO MRP}

O MRP, em síntese, é um sistema lógico de cálculo que converte a previsão de demanda em programação da necessidade de seus componentes. A partir do conhecimento de todos os componentes de um determinado produto e os tempos de obtenção de cada um deles, pode-se, com base na visão de futuro das necessidades, calcular o quanto e quando se deve obter de cada item, de forma que não haja falta e nem sobra no suprimento das necessidades da produção.

\section{Informações e Atividades}

As informações de entrada (input) e saída (output) indispensáveis para a elaboração do modelo de referência do módulo referente ao MRP estão expostas no Quadro 1.

Quadro 1 -Informações referentes ao MRP

\begin{tabular}{|l|l|}
\hline \multicolumn{1}{|c|}{ Input } & \multicolumn{1}{|c|}{ Output } \\
\hline Lista de materiais (BOM) & Necessidades brutas dos materiais \\
Período de planejamento de curto prazo & Estoques projetados dos materiais \\
Demanda bruta dos materiais & Recebimentos planejados dos materiais \\
Recebimentos programados dos & Pedidos liberados dos materiais \\
componentes & \\
Estoques iniciais dos componentes dos dequisitos dos materiais \\
$\begin{array}{l}\text { Níveis dos estoques de segurança dos } \\
\text { componentes }\end{array}$ \\
$\begin{array}{l}\text { Tamanhos dos lotes dos componentes } \\
\text { Regras dos tamanhos dos lotes dos } \\
\text { componentes } \\
\text { Prazos de entrega dos materiais }\end{array}$ \\
Tempo de montagem do produto final & \\
\hline
\end{tabular}

Fonte: própria (2018)

As atividades relacionadas a este módulo do planejamento do PCP, estão expostas, com seus respectivos referenciais teóricos, no Quadro 2. 
Quadro 2 - Sequência de atividades referentes ao MRP

\begin{tabular}{|c|c|c|}
\hline \# & Atividade & Referencial Teórico \\
\hline 1 & $\begin{array}{l}\text { Definição das listas de materiais (BOM) } \\
\text { dos produtos finais, oriundos do plano } \\
\text { mestre de produção. }\end{array}$ & $\begin{array}{c}\text { Girotti et al. (2016), Corrêa e Corrêa } \\
\text { (2012), Moreira (2008), Gaither e Frazier } \\
\text { (2005), Yenisey (2006) e Neely e Byrne } \\
\text { (1992). }\end{array}$ \\
\hline 2 & $\begin{array}{c}\text { Definição do período de planejamento } \\
\text { de curto prazo. }\end{array}$ & Corrêa e Corrêa (2012). \\
\hline 3 & Cálculo das necessidades brutas. & \multirow{3}{*}{$\begin{array}{c}\text { Girotti et al. (2016), Corrêa e Corrêa } \\
\text { (2012), Moreira (2008), Gaither e Frazier } \\
\text { (2005) e Carvalho, Silva Filho e } \\
\text { Fernandes (1998). }\end{array}$} \\
\hline 4 & Cálculo dos estoques projetados. & \\
\hline 5 & Cálculo dos recebimentos planejados. & \\
\hline 6 & Liberação de pedidos planejados. & $\begin{array}{l}\text { Girotti et al. (2016), Favaretto (2012), } \\
\text { Corrêa e Corrêa (2012) e Moreira (2008). }\end{array}$ \\
\hline 7 & $\begin{array}{l}\text { Verificação da necessidade de analisar } \\
\text { outro componente do BOM. }\end{array}$ & $\begin{array}{c}\text { Girotti et al. (2016), Corrêa e Corrêa } \\
\text { (2012), Gaither e Frazier (2005), Yenisey } \\
\text { (2006) e Neely e Byrne (1992). }\end{array}$ \\
\hline 8 & $\begin{array}{c}\text { Emissão do plano de requisito de } \\
\text { materiais. }\end{array}$ & \multirow{2}{*}{ Corrêa e Corrêa (2012). } \\
\hline 9 & $\begin{array}{c}\text { Revisão do plano de requisitos de } \\
\text { materiais, se necessário. }\end{array}$ & \\
\hline
\end{tabular}

Fonte: Autoria própria (2018)

A seguir será descrito a modelagem do módulo referente ao módulo MRP do modelo de referência, de acordo com as informações e atividades levantadas.

\section{Descrição do modelo}

O modelo de referência do Planejamento de Requisitos de Materiais (Figura 22) proposto traz, inicialmente, a definição das listas de materiais (BOM), uma lista estruturada de todos os componentes do produto final a ser planejado. As informações a respeito dos produtos finais são extraídas da etapa do MPS, que estabelece quais produtos serão feitos e em que datas.

Em seguida, é realizada a definição do período de planejamento (curto prazo), sendo que este espaço de tempo deve ser proveniente do período que foi estabelecido na etapa de planejamento anterior, isto é, no MPS.

Para o cálculo das necessidades brutas, é necessário extrair informações da lista de materiais a respeito da estrutura dos componentes em cada nível de produção, bem como a quantidade necessária a ser produzida para cada unidade de produção do componente (demanda bruta), de acordo com o plano mestre de produção dos produtos finais. Para cada nível planejado dos materiais necessários para a produção do produto final, são necessárias as informações dos pedidos liberados dos materiais dos níveis inferiores a fim de calcular a quantidade necessária (necessidade bruta).

Após o cálculo das necessidades brutas, é realizado o cálculo dos estoques projetados. Para isso, é necessário levar em considerações, além das necessidades brutas, os estoques provenientes do período de planejamento anterior ao atual, recebimentos programados, se houver, e, também, o nível de estoque de segurança. Caso no período atual de planejamento tenha algum 
pedido de produção a ser realizado (recebimentos planejados), de acordo com as necessidades brutas, o estoque projetado érecalculado.

Para o cálculo dos recebimentos planejados, deve-se verificar se o nível de estoque satisfaz as necessidades brutas do período de planejamento, respeitando sempre o nível estoque de segurança estabelecido na etapa anterior. Se o nível não satisfazer as necessidades, é calculado este valor, levando em consideração o tamanho do lote e a regra do tamanho do lote (Lote a Lote, Lote Fixo ou Lote Mínimo). Nesta etapa, o estabelecimento dos níveis de produção do MPS, leva em consideração as informações oriundas no CRP, a respeito da capacidade produtiva de curto prazo.

Após a definição dos recebimentos planejados, é estabelecido a liberação dos pedidos planejados de acordo com o prazo de entrega de cada material e o tempo de montagem do produto final planejado.

Uma vez definido a liberação de pedidos de determinado componente, é verificado se há a necessidade de analisar outro material do BOM, uma vez, como já foi dito, a lista de materiais possui níveis de planejamentos podendo, dessa forma, as quantidades de materiais (demanda bruta) serem dependentes de outros.

Depois de finalizada a liberação de pedidos planejados de todos os itens que compões o BOM do produto final, o plano de requisito de materiais é emitido. Em caso de necessidades, é possível a realização de uma revisão deste plano elaborado. Após a revisão, então, é emitido o plano consolidado do MRP.

Estas informações são requisitadas para o cálculo do plano da capacidade de curto prazo (CRP) e também para a análise e definição da Programação da Produção (PP) dos componentes e do produto final.

O modelo de referência, em notação BPMN, referente ao módulo do MRP está exposto na Figura 5, a seguir. 
Figura 5 - Modelagem do MRP em notação BPMN

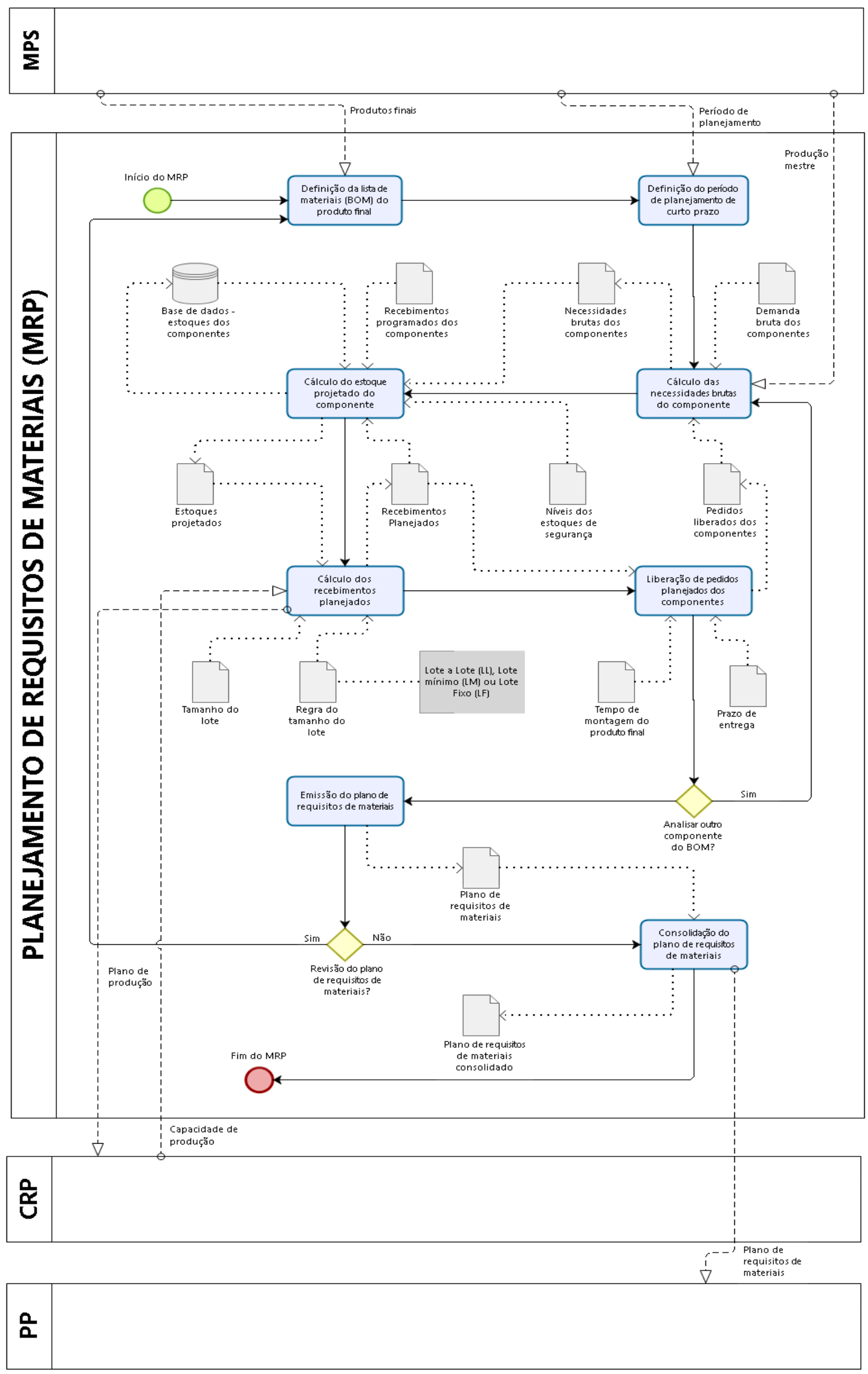

Fonte: Autoria própria (2018) 
O CRPvisa subsidiar as decisões do planejamento detalhado da produção e matérias. Este planejamento tem como objetivoocálculo das necessidades de recursos que requeiram prazo de poucas semanas para sua mobilização e, também, a geração de um plano detalhado de produção que seja viável, por meio de ajustes efetuados no plano original sugerido pelo MRP, para que este possa ser liberado para execução.

\section{Informações e Atividades}

As informações de entrada (input) e saída (output) necessárias para a elaboração do modelo de referência do módulo referente ao CRP estão expostas no Quadro 3.

Quadro 3 -Informações referentes ao CRP

\begin{tabular}{|c|c|}
\hline Input & Output \\
\hline Lista de matérias dos produtos finais & Capacidade necessária \\
Período de planejamento de curto prazo & Capacidade instalada \\
Dias úteis de trabalho & Taxa de carregamento \\
Jornada de trabalho diária & Plano da capacidade de produção de \\
Quantidade de mão-de-obra & curto prazo \\
Quantidade de mão-de-obra & \\
subcontratada & \\
Horas extras de trabalho diária & \\
Tempos de setup & \\
Taxas de produção & \\
Plano de produção & \\
\hline
\end{tabular}

Fonte: Autoria própria (2018)

As atividades relacionadas a este módulo do planejamento do PCP, estão expostas, com seus respectivos referenciais teóricos, no Quadro 4.

Quadro 4 - Sequência de atividades referentes ao CRP

\begin{tabular}{|c|c|c|}
\hline \# & Atividades & Referencial Teórico \\
\hline 1 & $\begin{array}{l}\text { Definição da lista de matérias (BOM) } \\
\text { dos produtos finais especificados no } \\
\text { MRP. }\end{array}$ & $\begin{array}{c}\text { Girotti et al. (2016), Corrêa e Corrêa } \\
\text { (2012), Moreira (2008), Gaither e } \\
\text { Frazier (2005), Yenisey (2006) e Neely e } \\
\text { Byrne (1992). }\end{array}$ \\
\hline 2 & $\begin{array}{c}\text { Definição do período de planejamento } \\
\text { especificado no MRP. }\end{array}$ & Corrêa e Corrêa (2012). \\
\hline 3 & $\begin{array}{l}\text { Levantamento das seguintes } \\
\text { informações referentes à capacidade } \\
\text { produtiva: quantidade da mão-de-obra } \\
\text { (normal e subcontratada). }\end{array}$ & \multirow[b]{2}{*}{$\begin{array}{c}\text { Corrêa e Corrêa (2012), Corrêa, Gianesi } \\
\text { e Caon (2009), e Mukhopadhyay } \\
\text { (2013). }\end{array}$} \\
\hline 4 & $\begin{array}{l}\text { Levantamento das seguintes } \\
\text { informações referentes ao tempo de } \\
\text { produção: jornada de trabalha diário, } \\
\text { hora extra de trabalho e os dias úteis } \\
\text { de trabalho de cada período de } \\
\text { planejamento. }\end{array}$ & \\
\hline
\end{tabular}




\begin{tabular}{|c|c|c|}
\hline 5 & $\begin{array}{l}\text { Levantamento da taxa de produção dos } \\
\text { componentes dos produtos finais. }\end{array}$ & \\
\hline 6 & $\begin{array}{l}\text { Cálculo da capacidade necessária de } \\
\text { produção dos componentes. }\end{array}$ & \multirow{2}{*}{ Corrêa e Corrêa (2012). } \\
\hline 7 & $\begin{array}{l}\text { Cálculo da capacidade instalada de } \\
\text { produção. }\end{array}$ & \\
\hline 9 & Cálculo da taxa de carregamento. & Martins e Laugeni (2009). \\
\hline 10 & $\begin{array}{l}\text { Elaboração do plano da capacidade de } \\
\text { produção de curto prazo. }\end{array}$ & \multirow[b]{2}{*}{$\begin{array}{l}\text { Mukhopadhyay (2013) e Corrêa, } \\
\text { Gianesi e Caon (2009). }\end{array}$} \\
\hline 11 & $\begin{array}{l}\text { Revisão do plano da capacidade de } \\
\text { produção de curto prazo, se } \\
\text { necessário. }\end{array}$ & \\
\hline
\end{tabular}

Fonte: Autoria própria (2018)

A seguir será descrito a modelagem do módulo referente ao módulo CRP do modelo de referência, de acordo com as informações e atividades elencadas.

\section{Descrição do modelo}

No modelo do CRP, como exposto na Figura 6, inicialmente é definido o tempo de planejamento de curto prazo, de acordo com o que foi estabelecido pelo MRP.

Em seguida, é calculado o tempo total de setup de todos os materiais do BOM presentes no processo produtivo.

Para a realização do cálculo da capacidade necessária de produção, leva-se em consideração a quantidade de materiais do produto final a ser planejado que estão descritos nos recebimentos planejados no plano de requisitos de materiais.

Para a efetivação desse cálculo, é necessário ter informações de duas variáveis pertinentes ao processo produtivo: taxa de produção destes materiais, quantidade de mão-de-obra disponível (normal e subcontratada), o plano de produção especificado no MRP, e os tempos totais de setup calculados na etapa anterior.

Seguidamente a descrição desta etapa do modelo, é realizado a consolidação da capacidade instalada de produção, que para seu cálculo deve-se levar em conta as seguintes variáveis: dias úteis de trabalho, jornada de trabalho e horas extras de trabalho, este último se houver.

Por fim, para o cálculo da taxa de carregamento do processo produtivo referente ao MRP, que é realizado através da razão entre o a capacidade total necessária de produção e a capacidade instalada de produção.

Após a realização desta última etapa, é emitido o plano da capacidade de curto prazo, necessário para a consolidação do MRP. Em caso de necessidades, é possível a realização de uma revisão deste plano elaborado. Após a revisão, então, é emitido o plano consolidado do CRP. Estas informações, como visto anteriormente, são requisitadas para a análise e definição do MRP.

O modelo de referência, em notação BPMN, referente ao módulo do MRP está exposto na Figura 6, a seguir. 
Figura 6 - Modelagem do CRP em notação BPMN.

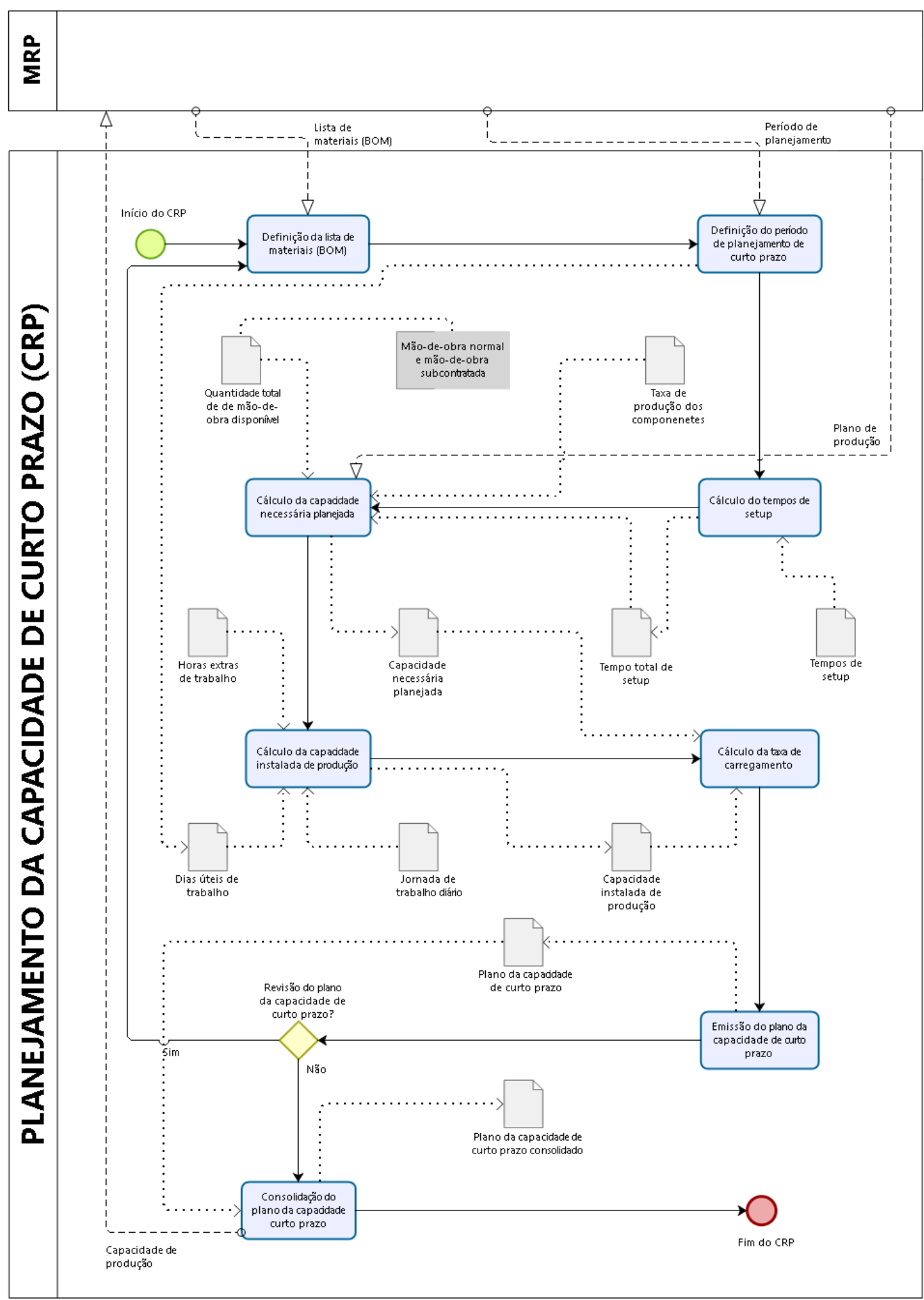

Fonte: própria (2018).

\section{PROTÓTIPO DO SOFTWARE}

Após a elaboração do módulo do sistema de planejamento da produção referente ao módulo do MRP do PCP, foi desenvolvido um protótipo de softwareatravés da interface Delphi, com a intenção de gerar uma maior consistência entre a abstração do modelo de referência e a sua aplicação no 
apoio a implantação e desenvolvimento de ferramentas de gestão empresarial, foi desenvolvido um protótipo do software através da interface Delphi. As telas do protótipo referente ao MRP e CRP estão sendo mostradas nas Figura 7, 8, 9 e 10.

Figura 7 - Primeira tela do protótipo do softwarede PCP do módulo do MRP e CRP

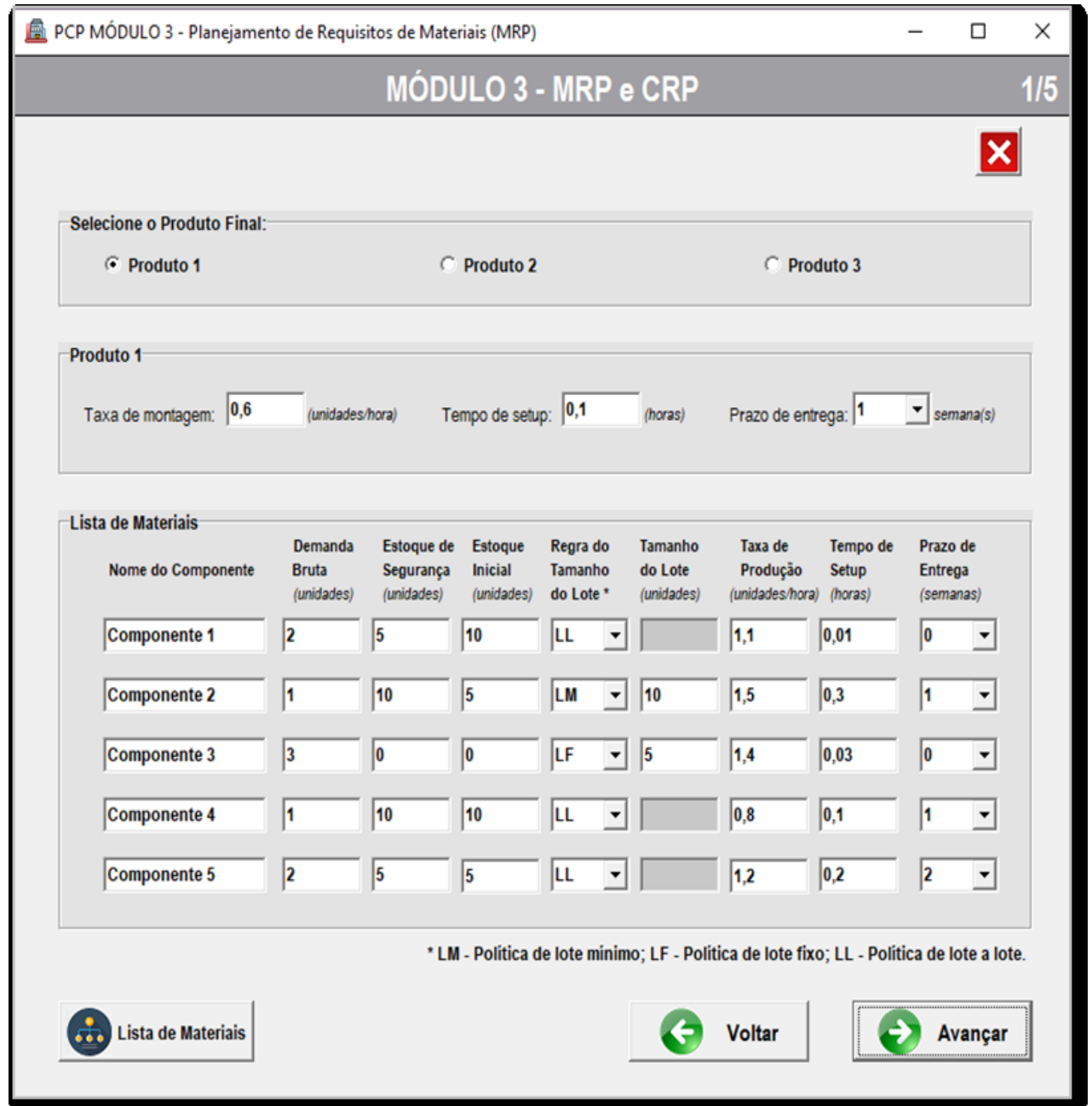

Fonte: Autoria própria (2018) 
Figura 8 - Segunda tela do protótipo do softwarede PCP do módulo do MRP e CRP

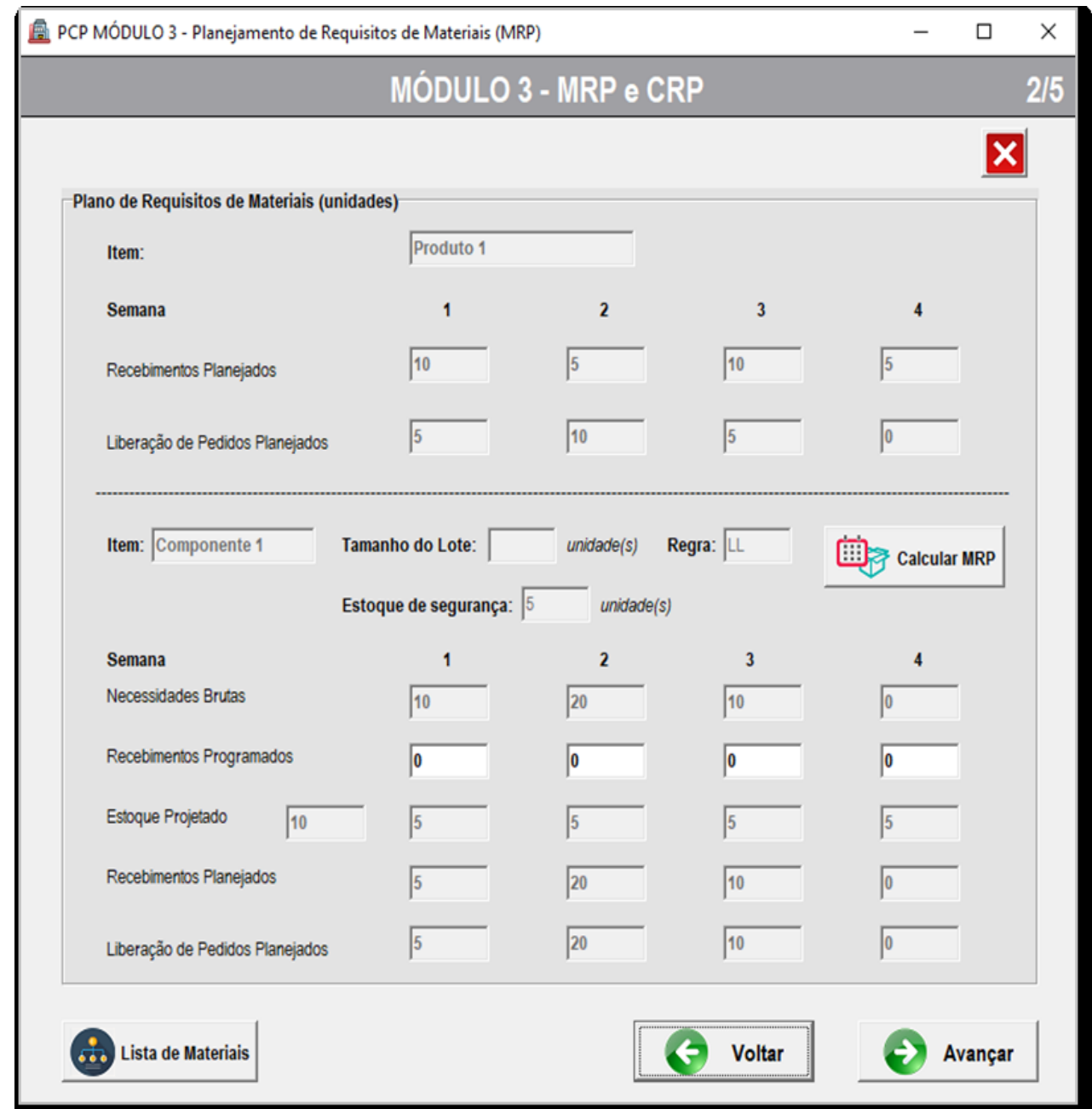

Fonte: Autoria própria (2018) 
Figura 9 - Terceira e quarta tela do softwarede PCP do módulo do MRP e CRP

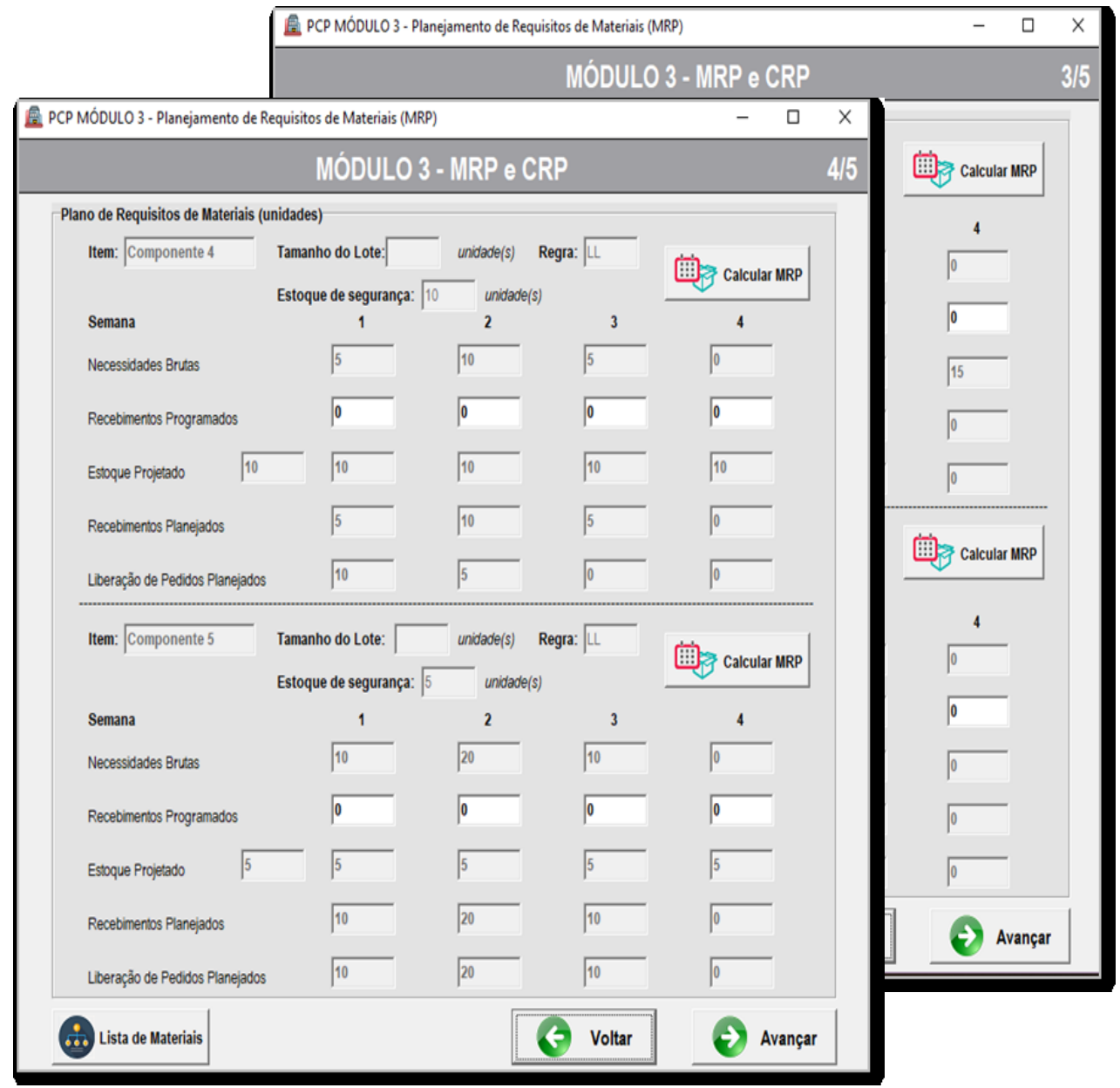

Fonte: Autoria própria (2018) 
Figura 10 -. Quinta tela do protótipo do software de PCP do módulo do MRP e CRP

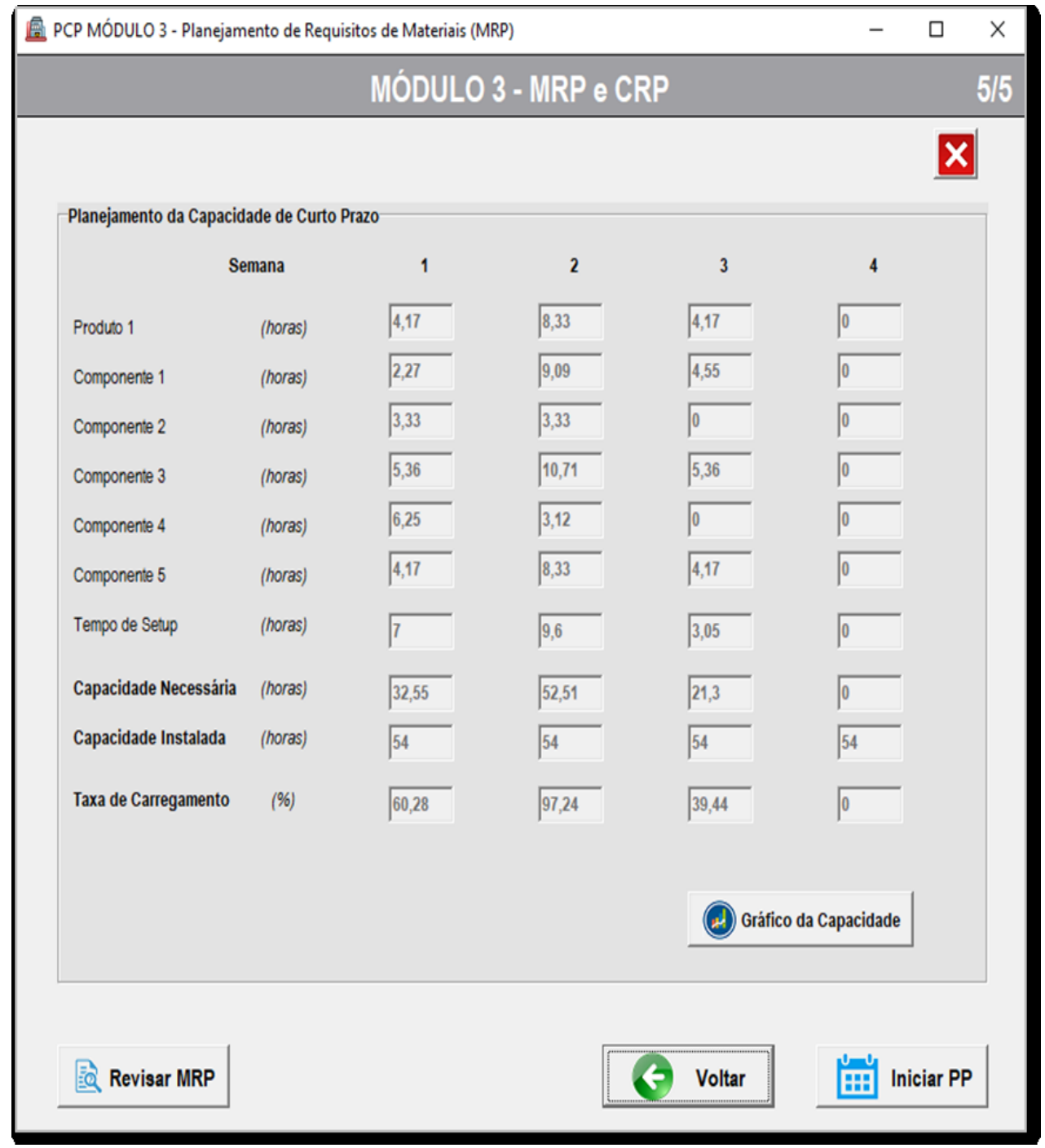

Fonte: Autoria própria (2018)

Para fins de validação do protótipo dosoftware, diversos testes foram realizados, com diferentes cenários de planejamento e estratégias de produção, com o objetivo de verificar, as atividades, informações, a exatidão e a precisão dos cálculos utilizados para a elaboração do plano mestre final.

Os resultados obtidos pelo programa computacional foram comparados com os resultados extraídos de forma manual e em planilhas eletrônicas de cálculo. Dessa forma, o protótipo do software elaborado a partir do modelo de referência desenvolvido, mostrou-se confiável e apto para ser utilizado para a elaboração de planos de requisitos de materiais da produção.

\section{CONCLUSÕES}

Atualmente, presenciamos uma crescente atenção no suporte ao desenvolvimento e implantação de ações de melhorias da gestão empresarial. 
Entretanto, a maioria de pesquisas e soluções para o planejamento da produção é focada em grandes e complexas organizações, realçando uma lacuna acadêmica acerca de trabalhos voltados para o apoio a implantação de sistemas de gestão, em especial, para as pequenas e médias empresas. Diante disso, o modelo de referência desenvolvido neste trabalho poderá prover a estas empresas com uma solução inicial para seus processos de negócios, a fim de especificar e detalhar o modelo particular com uma redução de custo e tempo de implantação.

Dessa forma, este trabalho buscou o desenvolvimento de um modelo de referência, em notação BPMN, que aborde os processos de negócios relacionados ao MRP, bem como ao CRP, um dos módulos inerentes ao PCP. Além disso, também objetivou desenvolver um protótipo de software com o intuito de aplicar este modelo em sistemas e ferramentas de gestão.

Como resultados, a partir de uma documentação formal, o modelo de referência mostrou-se uma ferramenta útil na compreensão e comunicação dos processos existentes no MRPS e CRP. Constatou-se também que este modelo desenvolvido está apto a dar apoio à implantação de sistemas de gestão da produção em situações reais. Entretanto, para a utilização em ambientes coorporativos, como por exemplo, na adoção de ERP, esses processos devem receber a atuação de especialistas e os usuários devem ter conhecimentos dos termos e variáveis envolvidos no modelo de referência.

Vale a pena destacar que o modelo de referência se configurou como uma importante ferramenta para a gestão do conhecimento, uma vez que esta é capaz de armazenar e documentar os conhecimentos existentes nos processos ne negócios e serve de base para planejar o desenvolvimento de novos conhecimentos, sempre sendo norteado pelos objetivos estratégicos da empresa.

Como continuação deste trabalho, está sendo desenvolvimento um modelo que aborde de forma holística e hierárquica os demais módulos dos Processos de Negócios relacionados ao PCP. Dessa forma, este modelo de referência visa preencher lacunas na literatura científica e avançar em relação aos modelos internacionais, uma vez que há carência de trabalhos a respeito de modelos de referência voltados para as atividades do PCP.

Para fins de validação e avaliação, sugere-se a divulgação e aplicação do software, desenvolvido a partir do modelo de referência, em pequenas e médias com atividades voltadas para o planejamento da produção. 


\title{
Proposal of a Reference Model in BPMN notation for an MRP system
}

\begin{abstract}
Companies are progressively investing in practices aimed at improving the quality of management, with the main purpose of enabling them to operate competitively in the present market. For this, it is necessary to document the activities and information of the existing business processes in the organization, aiming at reducing time and cost in the elaboration of the particular model. In this context, the objective of this work is to develop a reference model of the Materials Requirements Planning (MRP) processes, an important module of production planning and control (PPC). The research methodology used in this work was divided into the following stages: study of MRP and business process modeling, definition of reference model processes, choice of methodology and process modeling tool, development of reference model and prototype of the software and, finally, analysis of results. The modeling notation used was the BPMN, since it is considered a standard language in the field of process modeling. The prototype was developed through the Delphi interface in order to apply the model to support the implementation of business management programs. As results, from a formal documentation, the model proved to be a useful mechanism in the understanding of the processes raised and appropriate in the support to the implantation of production management tools.
\end{abstract}

KEYWORDS: Reference Model; Materials Requirements Planning; Business Process Model and Notation. 


\section{REFERÊNCIAS}

ABELE, E.; SCHREMS, S. Resource oriented assessment of alternative process chains. ZWF Zeitschrift fuer Wirtschaftlichen Fabrikbetrieb, v. 105, n. 6, p. 542546,2010 . crossref

AGUILAR, J.; CHACAL, J.; BRAVO, C. A multiagents systems for planning and management of the production factors. Computer Systems Science and Engineering, v. 24, n. 2, p. 85-102, 2009.

BOLLOJU, N.; LEUNG, F. S. K. Assisting Novice Analysts in Developing Quality Conceptual Models with UML. Commun. ACM, v. 49, n. 7, p. 108-112, jul. 2006. crossref

BREMER, C. F.; LENZA, R. DE P. A reference model for production management in assembly to order: ato production systems and its multiple applications. Gestão \& Produção, v. 7, n. 3, p. 269-282, dez. 2000. crossref

CHINOSI, M.; TROMBETTA, A. BPMN: An introduction to the standard. Computer Standards \& Interfaces, v. 34, n. 1, p. 124-134, jan. 2012. crossref

CORRÊA, H. L.; CORRÊA, C. A. Administração de produção e operações: manufatura e serviços - Uma abordagem estratégica. 2. ed. São Paulo: Atlas, 2012.

CORREA, J.; SPINOLA, M. DE M. Adoção, seleção e implantação de um ERP livre. Production, v. 25, n. 4, p. 956-970, dez. 2015. crossref

ENTRINGER, T. C. et al. Reference Models for Production Planning and Control Systems: A Bibliometric Analysis and Future Perspectives. International Journal of Advanced Engineering Research and Science, v. 5, n. 8, 2 set. 2018. crossref

ENTRINGER, T. C.; FERREIRA, A. DA S. Proposal for a Reference Model for Sales \& Operations Planning and Aggregate Planning. International Journal of Advanced Engineering Research and Science, v. 5, n. 8, p. 277-284, 2018. crossref

FAVARETTO, F. Impacto das incertezas da previsão da demanda no planejamento detalhado da produção. P\&D em Engenharia de Produção, v. 10, n. 1, p. 101-108, 2012. 
FERNANDES, F. C. F.; GODINHO FILHO, M. Planejamento e controle da produção: dos fundamentos ao essencial. São Paulo: Atlas, 2010.

GAITHER, N.; FRAZIER, G. Administração da produção e operações. 8a. ed. São Paulo: Pioneira Thomson Learning, 2005.

GIACON, E.; MESQUITA, M. A. DE. Levantamento das práticas de programação detalhada da produção: um survey na indústria paulista. Gestão \& Produção, v. 18 , n. 3, p. 487-498, 2011. crossref

GIROTTI, L. J. et al. Production Planning and Control: a survey of teachers in Production Engineering. Production, v. 26, n. 1, p. 176-189, mar. 2016.

GODINHO FILHO, M.; FERNANDES, F. C. F. MRP system: nervousness reduction and performance improvement. Production, v. 16, n. 1, p. 64-79, abr. 2006. crossref

GUERRA, R. M. DE A.; SCHUSTER, J. V.; TONDOLO, V. A. G. Implantação de um modelo de MRP em uma empresa de médio porte do setor moveleiro. Revista Gestão Industrial, v. 9, n. 4, 20 fev. 2014. crossref

JONSSON, P.; MATTSSON, S. A longitudinal study of material planning applications in manufacturing companies. International Journal of Operations \& Production Management, v. 26, n. 9, p. 971-995, 1 set. 2006. crossref

KELLER, G.; TEUFEL, T. SAP R/3 process-oriented implementation: iterative process prototyping. Harlow, England ; Reading, Ma: Addison Wesley Longman, 1998.

MENDES, M. R.; FILHO, L. C. DE B. A Experiência da Elaboração de um PCP: um Caso de uma Indústria de Alimentos. Revista de Engenharia e Pesquisa Aplicada, v. 2, n. 2, 27 jul. 2017. crossref

MEYER, W.; ISENBERG, R.; HUBNER, M. Knowledge-based factory supervision the cim shell. International Journal of Computer Integrated Manufacturing, v. 1, n. 1, p. 31-43, 1988. crossref

MILNE, R. J.; MAHAPATRA, S.; WANG, C.-T. Optimizing planned lead times for enhancing performance of MRP systems. International Journal of Production Economics, v. 167, p. 220-231, 1 set. 2015. crossref 
MUKHOPADHYAY, S. K. Production planning and control: text and cases. 2. ed ed. Delhi: PHI Learning, 2013.

NEELY, A. D.; BYRNE, M. D. A simulation study of bottleneck scheduling. International Journal of Production Economics, v. 26, n. 1, p. 187-192, 1 fev. 1992. crossref

ORNEK, A. M.; CENGIZ, O. Capacitated lot sizing with alternative routings and overtime decisions. International Journal of Production Research, v. 44, n. 24, p. 5363-5389, 15 dez. 2006. crossref

PANDEY, P. C.; YENRADEE, P.; ARCHARIYAPRUEK, S. A finite capacity material requirements planning system. Production Planning \& Control, v. 11, n. 2, p. 113121, 1 jan. 2000.

crossref

RECKER, J. C. Opportunities and constraints : the current struggle with BPMN. Business Process Management Journal, v. 16, n. 1, p. 181-201, 2010. crossref

SAGBANSUA, L. Information Technologies and Material Requirement Planning (MRP) in Supply Chain Management (SCM) as a Basis for a New Model. Bulgarian Journal of Science and Education Policy, v. 4, n. 2, p. 236-247, 1 nov. 2010.

SCHEER, A.-W. ARIS - Business Process Frameworks. 3. ed. Berlin, Heidelberg: Springer Berlin Heidelberg, 2000. crossref

SIAU, K. Informational and Computational Equivalence in Comparing Information Modeling Methods. Journal of Database Management (JDM), v. 15, n. 1, p. 73-86, 1 jan. 2004. crossref

SIAU, K.; ROSSI, M. Evaluation techniques for systems analysis and design modelling methods - a review and comparative analysis. Information Systems Journal, v. 21, n. 3, p. 249-268, 1 maio 2011. crossref

TAAL, M.; WORTMANN, J. C. Integrating MRP and finite capacity planning. Production Planning \& Control, v. 8, n. 3, p. 245-254, 1 jan. 1997. crossref

TATSIOPOULOS, I. P.; MEKRAS, N. D. An expert system for the selection of production planning and control software packages. Production Planning and Control, v. 10, n. 5, p. 414-425, 1999. crossref

THURER, M.; FILHO, M. G. Redução do lead time e entregas no prazo em pequenas e médias empresas que fabricam sob encomenda: a abordagem 
Worload Control (WLC) para o Planejamento e Controle da Produção (PCP). Gestão \& Produção, v. 19, 2012. crossref

VERNADAT, F. Enterprise modeling and integration: principles and applications. London ; New York: Chapman \& Hall, 1996.

VERNADAT, F. B. Enterprise Modelling and Integration. In: KOSANKE, K. et al. (Eds.). . Enterprise Inter- and Intra-Organizational Integration. Boston, MA: Springer US, 2003. p. 25-33. crossref

VOJISLAV, B.; LEON, J. Evaluating the Quality of Reference Models. Conceptual Modeling - ER 2000. Anais...: Lecture Notes in Computer Science. In: INTERNATIONAL CONFERENCE ON CONCEPTUAL MODELING. Springer, Berlin, Heidelberg, 9 out. 2000. Disponível em: <https://link.springer.com/chapter/10.1007/3-540-45393-8_35>. Acesso em: 12 dez. 2017

YENISEY, M. M. A flow-network approach for equilibrium of material requirements planning. International Journal of Production Economics, v. 102, n. 2, p. 317-332, 1 ago. 2006. crossref

ENTRINGER, T.C. et al. Proposta de um modelo de referência em notação BPMN para um sistema de MRP

R. Gest. Industr., Ponta Grossa, v. 15, n. 4, p. 140-165, Out./Dez. 2019. Disponível em:

http://periodicos.utfpr.edu.br/revistagi. Acesso em: 2019.

Correspondência:

Tulio Cremonini Entringer

Universidade Estadual do Norte Fluminense Darcy Ribeiro, Brasil.

Direito autoral: Este artigo está licenciado sob os termos da Licença Creative Commons-Atribuição 4.0

Internacional.

\section{(c) (1)}

